\title{
Fouled snails in flow: potential of epibionts on Littorina littorea to increase drag and reduce snail growth rates
}

\author{
Martin Wahl* \\ Zoologisches Institut, University of Kiel, D-24098 Kiel, Germany
}

\begin{abstract}
Epibiosis is one of the closest interspecies associations. The presence of epibionts potentially causes a multitude of beneficial or detrimental effects for the basibiont. It has been shown previously that large epibionts may increase the risk of dislodgement of bivalves. In this study, sublethal effects of epibiont-induced drag increase are investigated. I assessed (1) the effects of common epibiont species (Balanus improvisus, Enteromorpha intestinalis, Ectocarpus sp.) on drag properties of the host (the periwinkle Littorina littorea), and (2) the long-term consequences of drag increase on growth rates of snails living in steady flow. All epibiont species increase drag on the host snail. They do so to unequal extents. This may be due to morphological and hydrodynamic differences among the epibionts. Thus, per unit volume of epibiont, the filamentous alga Ectocarpus sp. has a substantially stronger effect than the barnacles. Synergistic effects on drag increase can be observed in a mixed aufwuchs community. As compared to clean conspecifics, snails bearing artificial epibionts grow $35 \%$ more slowly when exposed to moderate, steady flow $\left(8 \mathrm{~cm} \mathrm{~s}^{-1}\right)$ for $5 \mathrm{mo}$. This difference in growth rates is enhanced when food is limited. I hypothesize that fouled snails coping with higher drag invest more energy into foot activities (muscles and mucus). As a consequence, when food is limited, growth rates decrease in fouled snails
\end{abstract}

KEY WORDS: Littorina littorea. Drag - Epibiosis - Epibiosis costs . Growth rates Energy budget

\section{INTRODUCTION}

Of all interspecific associations, epibiosis is one of the most intimate. Basibiont and epibiont species live in close spatial association often for the entire lifespan of at least one of the organisms. Direct and indirect interactions between basibiont and epibiont are numerous (reviewed in Wahl 1989). Furthermore, the presence of an epibiotic community on the body surface of a basibiont can be expected to modify the interaction of the latter with its environment.

Thus, the insulating effect of an epibiotic cover may hinder uptake of food and excretion of wastes, but also protect a temporarily emersed basibiont from desiccation, irradiation or desalination (e.g. Dayton 1971, Penhale 1977), or from detection by a predator (e g. Vance 1978, Feifarek 1987).

•E-mail: mwahl@zoologie.uni-kiel.de
Besides this mere camouflage effect, the deterrent or attractive presence of epibionts at the interface between basibiont and environment may decrease ('associational resistance') or increase ('shared doom') predation pressure (e.g. Bloom 1975, Feifarek 1987, Barkai \& McQuaid 1988, Wahl \& Hay 1995).

A further interaction between an aquatic organism and the surrounding medium may be modulated by the mere physical presence of epibionts. When water passes around an aquatic organism, the latter is subject to 3 main hydrodynamic forces: drag, lift and acceleration (the latter only in unsteady flow). It is irrelevant in this case whether it is the water or the organism or both that are moving. This study on Littorina littorea focuses on drag, which presumably is the most relevant for the relatively heavy snails, especially in the Baltic Sea subtidal where steady flows dominate. The intensity of drag depends on several physical parameters such as the velocity difference between 
organism and water body, the viscosity and density of the water, and the Reynolds number (Vogel 1981, Gaylord et al. 1994), but also on the biological properties of the organism in question: size, shape, surface-tovolume ratio, surface topography, wettability and elasticity. Epibiosis has the potential to dramatically influence some or all of these biological characteristics when a basibiont/water interface is replaced by an epibiont/water interface. Different epibiont/basibiont pairings can be expected to shift these parameters to different extents and/or in different directions. Size will always incrcase. The new shape of the 'compound' organism will depend on the morphology and spatial arrangement of the epibionts. Smooth, encrusting epibionts on rough basibionts (e.g. certain sponges on bivalves) may reduce surface-to-volume ratio and roughness. But more often surface will increase and the topography becomes more complexly structured through epibiosis. Weltability and elasticity may increase or decrease depending on who is overgrowing whom. Thus, epibiosis will usually alter at least some drag-relevant properties of a basibiont, and we may expect that drag will be different on clean as compared to fouled conspecifics under otherwise identical conditions. Both epibiosis-caused increase and decrease of drag have been described. Macroalgae growing on mussels may increase drag to a point where the basibionts are torn lose from the substratum (Witman \& Suchanek 1984, Ansell et al. 1988). On the other hand, hydrophobic epibiotic bacteria have been reported to substantially reduce drag on fast swimming fishes (Sar \& Rosenberg 1987).

The periwinkle Littorina littorea is a common interand subtidal snail of many Atlantic coasts. Its shell is often colonized by various epibionts like ciliates, hydrozoans, scyphozoan polyps, sessile polychaetes, barnacles and algae. In the Western Baltic, the epibiotic community on some snails may attain a mass equal to the snail's and 2 or 3 times its volume. Shell epibionts which frequently dominate by mass and volume are the barnacles Balanus improvisus or $B$. crenatus, the filamentous brown alga Ectocarpus sp. and the green alga Enteromorpha sp. It is likely that in a non-stationary environment this sort of epibiosis influences drag on the snails.

By changing the drag properties of a snail, epibiosis could affect the amount of energy the snail has to invest in locomotion and adhesion. Both necessitate muscular activity and secretion of pedal mucus, Little is known about the proportion of the total energy budget spent for the muscular part of foot activity (crawling and attachment), although Grenon
\& Walker (1981) report that limpet foot tonus and adherence are impaired under physiological stress, suggesting that foot muscle activity is costly On the other hand, Davies et al. (1992) state that 'mucus production is by far the costliest component of locomotion' and that it represents a large proportion of the total energy budget.

Consequently, epibiosis, by affecting drag, should influence the energy budget of fouled snails in flow and-indirectly-affect reproduction and/or growth rates, at least under conditions where food is limiting.

In this study, I address the following questions: Do epibionts on Littorina littorea affect drag on the snail? Do different epibiotic species affect drag differently, maybe even in opposite directions? Does increased drag under steady flow conditions influence growth rates of the snails? In this study, attention was focused on the in-line component of drag The 2 other components, lift and accelerational force, are presumably of minor importance for the relatively heavy snails in steady flow.

\section{MATERIAL AND METHODS}

Epibiosis and drag increase. Fouled Littorina littorea were collected from 1 to $3 \mathrm{~m}$ depth at our experimental station near Kiel, Germany (Western Baltic, $54^{\circ} 26^{\prime} \mathrm{N}, 10^{\circ} 10^{\prime} \mathrm{E}$ ). Drag was assessed for snails fouled by Enteromorpha intestinalis, Balanus improvisus, Ectocarpus sp., a mixed Balanus/Ectocarpus community and for the same snail individuals after cleaning (Fig. 1). Drag measurements were done using a recirculating sea-water flume described below. The setup for measuring drag is shown in Fig. 2: a thin
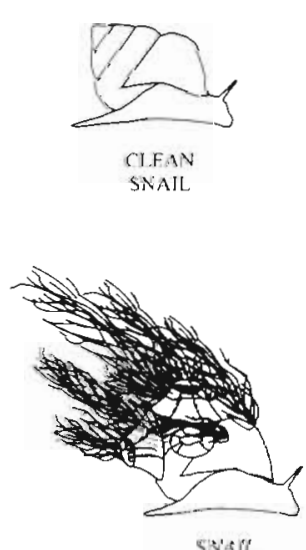

FOULED BY BALANUS ANDECTOCARPUS
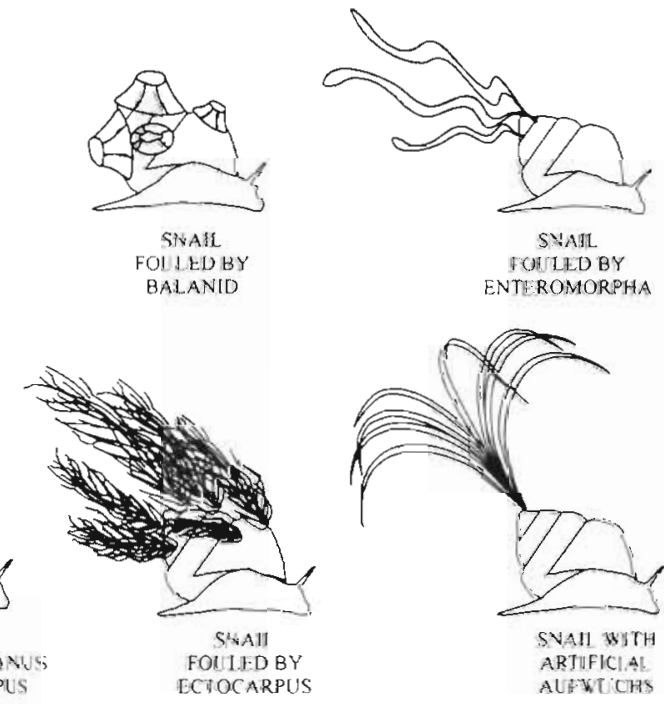

Fig. 1. Aspects of clean, naturally and artificially fouled Littorina littorea 
Fig 2. Experimental setup for drag measurements conly the experimental section of the flume is illustrated). 1: snail on measuring platform, 2: measuring platform, 3: monofilament connecting platform to lever, 4 : lever transmitting pull to weight $(1: 1)$, 5: electronic balance (precision: $0.0001 \mathrm{~g}$ ), 6: bottom plate of bed of experimental section

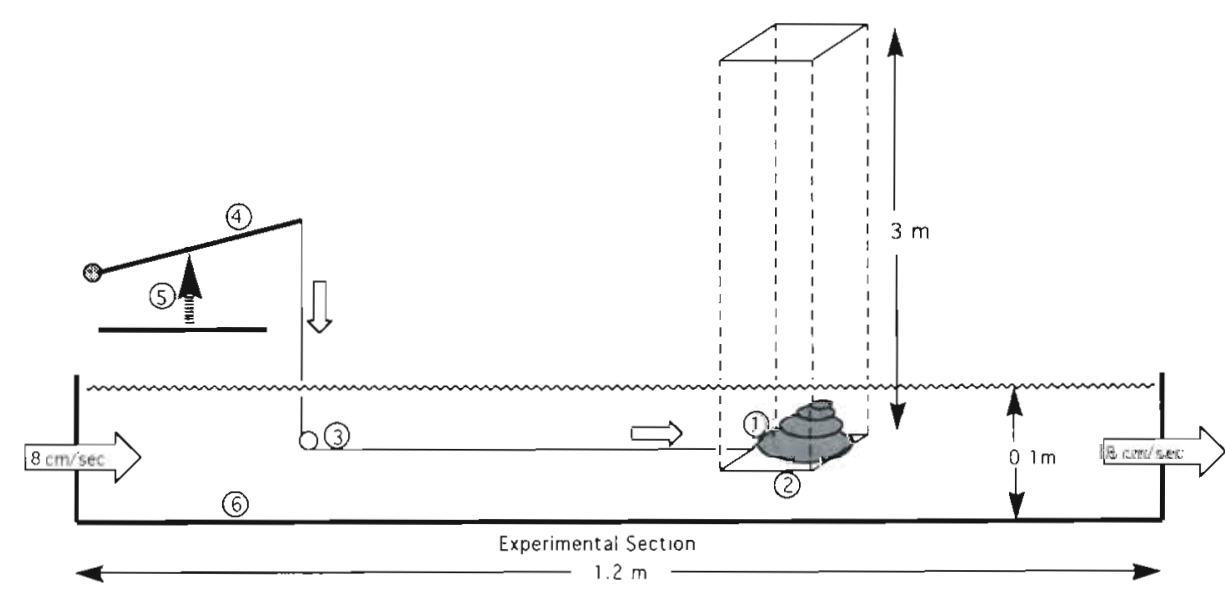

glass plate $(5 \times 5 \mathrm{~cm}, 1 \mathrm{~mm}$ thick $)$ was suspended by four $3 \mathrm{~m}$ long, thin monofilaments from an identical plate attached to the roof of the constant temperature room $\left(15^{\circ} \mathrm{C}\right)$. This arrangement allowed a small lateral displacement of the platform (caused by drag on the platform without or with snail) while the orientation of the platform remained horizontal. The slight vertical rise of the platform $(<0.5 \mathrm{~cm})$ during displacement was considered negligible since the position of the platform was about $4 \mathrm{~cm}$ above the bed's boundary layer. The in-line pull on the platform as an effect of drag was translated to vertical pull via a thin monofilament running from the platform, under a transversely arranged, horizontal glass tube, to a lever. The pull on the lever was transmitted in a 1:1 relation onto an electronic balance. Thus, horizontal drag on the platform or on snail plus platform could be registered as a 'weight' on the balance to the nearest $0.0001 \mathrm{~g}$. 'Weight' data $(\mathrm{g})$ were subsequently transformed to force units $(\mathrm{mN})$. To reduce variance in readings (probably due to small turbulences of flow or snail posture), every drag measurement was repeated 5 times, manually resetting the balance between readings, and averaged. Snails were positioned 'head upstream' onto the platform. Drag readings for all snails were done in the same position, i.e. when the snail started crawling upstream with head and foot extruded. The standard measuring sequence for all snails was: (1) empty platform, (2) fouled snail, (3) snail cleaned from secondary epibionts (if present), (4) totally cleaned snail and again (5) empty platform. Drag on epibionts and snails were calculated by the appropriate subtractions. Unless explicitly stated otherwise, all drag measurements and experiments were done at a flow speed of $8 \mathrm{~cm} \mathrm{~s}^{-1}$.

Effects of epibiont-caused drag increase on snail growth. An experiment designed to assess the effect of increased drag on the growth rate of snails was conducted in the same flume as described above. Fouled and clean snails were exposed to identical flow, nutritional and water quality conditions, while growth was monitored from February through July 1995.

This time, the flume was set up in the open on a dock in Kiel fjord, enabling us to work under near-natural conditions (light regime, temperature, water quality, etc.). Flow velocity was $8 \mathrm{~cm} \mathrm{~s}^{-1}$, which is a common local current velocity. Flow was stopped twice per day for 15 min to allow those snails that might have lost their hold to re-attach. The flume was flushed twice per day for 30 min by means of a submersible pump (ca $20 \mathrm{lmin}^{-1}$ ) to renew the tank water and to allow the continuous recolonization of surfaces grazed by the snails.

Test snails were attached to the bottom of the experimental section in the following manner. For each snail, a monofilament line attached to a hole drilled into the shell rim was threaded through a $0.2 \mathrm{~mm}$ hole drilled through the bottom plate and fixed on the underside to a PE washer. The washer, being slightly heavier than seawater, kept the line straight during locomotion. The length of the monofilament was $7 \mathrm{~cm}$, defining the radius of the circular grazing area. The arrangement of the holes was as follows. A total of 21 holes were arranged in 7 transverse rows of 3 holes each. The distance between neighboring holes was $15 \mathrm{~cm}$, the distance between outer holes and sidewall was $9 \mathrm{~cm}$ and the distance between first/last row to the ends of the experimental section was $30 \mathrm{~cm}$.

Twenty-one snails collected near the test site were thoroughly cleaned of epibionts by brushing and randomly assigned to a 'fouled' (11 individuals) or 'clean' batch (10 individuals). As the physical properties of 'epibionts' should stay constant during the experiment, I chose to glue artificial algae (a $2 \mathrm{~cm}$ long palmtree-shaped, neutrally buoyant segment of a plastic aquarium plant) by means of a drop of Z-Spar Splash Zone cement onto the apex-near end of the fouled snails, while clean snails only received the 
Table 1 Comparison of initial characteristic parameters of fouled and clean snails. Drag measurements: all snails = snails of both groups prior to treat ment; fouled snails = snails bearing cement drop and artificial alga ${ }_{\text {i }}$ clean snails = snails with cement drop only

\begin{tabular}{|lccl|}
\hline Parameter & All snails & Fouled snails & Clean snails \\
\hline Shell length $(\mathrm{mm})$ & $15.6(1.8)$ & $15.7(1.8)$ & $15.5(1.8)$ \\
Shell width $(\mathrm{mm})$ & $11.3(1.2)$ & $11.5(1.2)$ & $11.2(1.2)$ \\
Wet weight $(\mathrm{g})$ & $1.28(0.35)$ & $1.29(0.36)$ & $1.26(0.36)$ \\
Drag $(\mathrm{mN})$ & $0.48(0.17)$ & $2.34(0.48)$ & $0.6(0.24)$ \\
Factor of drag increase by treatment & $5.3(2.4)$ & $1.4(0.5)$ \\
\hline
\end{tabular}

c1). After 2 wk (29 May) brushing frequency was reduced to once per week (Period C2).

After the experiment, the 'palmtrees' and cement drops were carefully scraped off. Wet weight and shell length were measured. Then the snails were killed by deep-freezing. After thawing, the snails were extracted from their shell. Dry weights of snail body and shell were registered after drying for $72 \mathrm{~h}$ at $60^{\circ} \mathrm{C}$. Additionally, the largest and smallest radius ( $a$ and $b$, respectively) of the ellipsoid oper-

drop of cement in the same shell location. Prior to this treatment, wet weight, shell width and shell length were measured. The snails of the 2 batches, after the attachment of the 'palmtrees' to one batch, resembled each other in all parameters but drag (Table 1). The treatments cement-plus-palmtree and cement-only increased drag as compared to pretreatment snails by the factors 5.3 and 1.4 , respectively. The fouled and clean snails were attached to the bottom plate of the flume's experimental area in an alternating pattern.

Every 4 to 8 wk (19 April, 16 May, 29 June and 20 July 1995), the width of the shells was measured to the nearest $0.1 \mathrm{~mm}$. These monitoring dates define the ends of the growth periods A, B, C1 and C2, respectively. The only parameter of shell growth accessible during the experiment was width. To ascertain whether changes of shell width gave an accurate idea of growth, I correlated shell width and wet weight as measured on 25 snails of different sizes. This correlation was very close $(\rho=0.98)$ and significant $(p<$ 0.0001 ) as analyzed by a Spearman Rank Correlation. Thus, changes of shell width should truthfully reflect snail growth.

The flume was inspected weekly to monitor grazing activity (cleared zones around each snail) of the snails and to clean snail shells from overgrowth which might change their drag characteristics. Additionally, food abundance (thickness and density of microalgal biofilm) was visually estimated as 'absent', 'sparse', 'dense' or 'rich'.

By early summer, extreme colonization rates by diatoms and macroalgae led to an over-abundance of food available to the snails: apparently the snails found sufficient food in the immediate vicinity of their mouths without moving around. The snails became sedentary. Feeding and locomotion were decoupled. As increased locomotion costs for fouled snails was one of the possible epibiosis effects I wanted to assess, starting on 16 May the bottom plate was cleaned every other day ( 3 times per week) from attached organisms by brushing to artificially reduce available food (Period cula were measured to the nearest $0.1 \mathrm{~mm}$. Operculum area was calculated as $A=a b \pi$.

During Period $\mathrm{C} 1$, a fouled and a clean snail died. They were excluded from analyses involving $\mathrm{C} 1$ and C2 monitoring data.

Hydrodynamics of the flume experiments. Formulas for some parameters used for the analysis of results (mostly after Vogel 1981, Ekaratne \& Crisp 1984, Nowell \& Jumars 1987, Gaylord et al. 1994) were as follows

Reynolds number:

$$
\begin{aligned}
& \operatorname{Re}_{\text {(flume) }}=\rho / U / \mu \\
& \operatorname{Re}_{\text {(snâl) }}=4 r U /(\mu / \rho)
\end{aligned}
$$

where $\rho$ is density of medium; $I$ is distance from water entrance; $r$ is hydraulic radius (current-transverse cross section/wetted circumference); $U$ is water velocity; $\mu$ is dynamic viscosity; $\mu / \rho$ is kinematic viscosity)

\section{Drag coefficient:}

$$
C_{d}=2 D / \rho S U^{2}
$$

where $D$ is drag; $S$ is current-transverse frontal area of organism; $U$ is water velocity at upstream rim of measuring platform) or

$$
C_{d}=(\operatorname{Re})^{d}
$$

The exponent a can be computed from the independently obtained $C_{d}$ and $R e$ of the in vitro experiment:

$$
a=\log C_{d \text { (vitro })} / \log \operatorname{Re}_{\text {ivitro) }}
$$

Boundary layer thickness (defined as the water layer covering a surface, where water velocity increases with distance from the surface from zero to $99 \%$ free stream velocity):

$$
\begin{aligned}
& \partial_{\text {(snail) }}=0.33 \sqrt{ }(d / U)+2.9 / U \\
& \partial_{\text {(flume) }}=5 \sqrt{ }\left(x \rho \mu^{-1} U^{-1}\right)
\end{aligned}
$$

where $d$ is diameter of 'spherical' snail; $x$ is distance from water entrance

\section{Froude number:}

$$
F=U / \sqrt{ } g \partial
$$

where $U$ is free stream velocity; $g$ is gravitational acceleration; $\partial$ is boundary layer thickness. 
Bertalanffy growth coefficient correcting for the influence of snail size on growth rates:

$$
K=(\mathrm{d} H / \mathrm{d} t)(H \max -H)^{-1} \quad\left[\text { unit: } \mathrm{d}^{-1}\right]
$$

where $(\mathrm{d} H / \mathrm{d} t)$ is growth rate: I used length increase over 168 d in comparison with Ekaratne \& Crisp's (1984) data, $\max _{[l\}}$ is maximum local shell length (24 $\mathrm{mm}$ in this locality); $H_{(1)}$ is individual shell length. In all other cases, snail widths were used: $\operatorname{Hmax}_{(w)}$ is $17 \mathrm{~mm}, H_{[\mathrm{w}]}$ is individual snail width.

The flume measured $3 \mathrm{~m}$ long, $0.5 \mathrm{~m}$ wide and $0.5 \mathrm{~m}$ high (Fig. 2). The working section was $0.5 \times 1.2 \mathrm{~m}$ with a flow depth of $0.1 \mathrm{~m}$. Three serial blocks $(0.5 \times 0.15 \times$ $0.1 \mathrm{~m}$ ) composed of $0.1 \mathrm{~m}$ long and $0.01 \mathrm{~m}$ wide, thinwalled tubes served as flow straighteners. Water velocity was fixed at $8 \mathrm{~cm} \mathrm{~s}^{-1}$

This study's experimental setup comes close to or fulfills most of Nowell \& Jumars' (1987) prerequisites for low-turbulence flow: identical cross-sections throughout, a depth-to-width ratio of the working section of 1:5, tubes of the flow straighteners with a diameter-to-length ratio of 10 , a Reynolds number below $1000(\leqslant 3000)$, a lower-than-1 Froude number (between 0.2 and 0.4 here), a smooth-bedded experimental section. As expected, the flow in the working section was close to laminar, as confirmed by visualization of flow using clouds of coffee milk. The presence of the 21 snails in the growth experiment undoubtedly introduced some turbulence to the system, which probably cumulated from the first snail row (upstream) to the last (downstream). At the velocity used, the thickness of the boundary layer on the bottom plate of the experimental section increased from about $1 \mathrm{~cm}$ for the first snail row to about $1.75 \mathrm{~cm}$ for the last snail row (from $30 \mathrm{~cm}$ after water entrance to $30 \mathrm{~cm}$ before water exit). Thus, upstream snails possibly experienced shightly faster but calmer flow, whereas downstream snails were confronted with a little more turbulence while being sheltered by a slightly thicker boundary layer. Even if these 2 factors did not cancel out with regard to drag on individual snails, the potential gradients should not affect the results obtained for 3 reasons: (1) only relative differences between fouled and clean snails were of interest, and these were distributed alternately over the experimental section of the flume; (2) in each row (perpendicular to flow), fouled and clean snails lived in similar boundary layers and turbulence regimes: and (3) to compensate for turbulence and/or boundary layer gradients in the experimental section the bottom plate carrying the 21 snails was rotated weekly by $180^{\circ}$, inversing upstream/downstream and right/left positions of the snails. Consequently, average hydrodynamic conditions during the 5 mo experiment should have been sufficiently similar for all snails.
Under the given experimental conditions of slow and steady flow, the snails lived in a relatively viscous medium (low Re). While the drag coefficient for clean snails calculated for the in vitro drag measurements $\left(C_{d}\right.$ $=0.986$ ) was a constant (stable flow, temperature and salinity, and rigid organism shape), it may have increased slightly during the in situ growth experiment: mean shell length increased by about $7 \%$, and the kinematic viscosity of seawater changed from 1.47 to $1.15\left(\times 10^{-6} \mathrm{~m}^{2} \mathrm{~s}^{-1}\right)$ due to seasonal warming from $6^{\circ} \mathrm{C}$ in February to $16^{\circ} \mathrm{C}$ in July. Consequently, the Reynolds number rose during this period from $6.3 \times 10^{2}$ to $8.9 \times$ $10^{2}$, but with this crude index only order-of-magnitude changes are of biological significance (Vogel 1981).

Under these hydrodynamic conditions (low Re and $C_{d}$ near unity), drag depends more on size and shape than on surface characteristics such as roughness or wettability (Vogel 1981, Gaylord et al. 1994).

Statistics. As not all data were distributed normally, only non-parametric tests were employed.

Dependent samples: Repeated measurements on a same batch of individuals (e.g. drag-increase by epibionts, time-sequence change of growth rates for a given treatment group of snails) were compared by a Friedman test ( $>2$ dependent samples) and/or by a Wilcoxon Signed Rank test (2 dependent samples).

Independent samples: Comparisons between different batches of snails (e.g. sizes, drag or growth rates of fouled versus clean snails) were done by a $U$-test.

Covariation of variables (e.g. width versus wet weight of snails) was tested by a Spearman Rank Correlation.

\section{RESULTS}

\section{Hydrodynamics of clean snails}

The clean snails could (very roughly!) be considered to be of spherical shape, with a mean diameter of about $10 \mathrm{~mm}$ and a mean current-transverse frontal area of $140 \mathrm{~mm}^{2}$. Locomotory speed of the snail relative to current velocity was negligible. Average drag on all clean snails was 0.48 (SD 0.17) $\mathrm{mN}$.

Under these experimental conditions, the Reynolds number was about $8 \times 10^{2}$. The drag coefficient for clean snails was $C_{d}=0.9857$. This value comes closest to the solid sphere data as compared to those of other geometrical shapes given by Gaylord et al. (1994), confirming the previous assumption on snail shape. Finally, the thickness of the boundary layer around snails and on the measuring platform at the position of the snail was approximately $5 \mathrm{~mm}$ (Eq. 3).

On individual snails, drag did correlate well with flow velocity (Spearman Rank Correlation, $\mathrm{p}=0.004$, 
$\rho=0.75)$. On average, clean snails per $\mathrm{ml}$ body volume experienced a drag of $0.5 \mathrm{mN}(\mathrm{SD} 0.24)$ at a flow speed of $8 \mathrm{~cm} \mathrm{~s}^{-1}$ and $1.27 \mathrm{mN}$ (SD 1.3) at $12 \mathrm{~cm} \mathrm{~s}^{-1}$. Surprisingly, the relation between drag and velocity seems to be almost linear, at least for the limited range of velocities and the small number of snails tested in this regard $(n=3)$. Very roughly, drag triples when velocity doubles.

\section{Drag on fouled snails}

Epibionts increase drag on their snail hosts as compared to the latter's scraped-clean status (Wilcoxon: $\mathrm{p}$ $=0.0001)$. On average, epibiosis increased drag by a factor of 2 (geometric mean 2.04, median 1.87, range 1 to 20.92). The amount of drag increase depended on quantity and species of epibionts.

Enteromorpha intestinalis. This green alga grew sparsely on 3 snails. The algal volume attached to the basibiont only represented between 1.9 and $4.4 \%$ of the clean snail's volume. On average, drag was not increased significantly by this epibiosis. However, the potential importance of $E$. intestinalis epibiosis is illustrated by the fact that drag on snails fouled by this alga is more closely related to flow speed than that of the same host individuals after cleaning (Spearman: $p=$ 0.88 and $p=0.0007$ versus $\rho=0.75$ and $p=0.004, n=$ 16 in both cases).

Ectocarpus sp. On 9 snails, this brown filamentous alga grew abundantly. On average, the volume of this epibiont relative to its clean host snail was $24.8 \%$ (SD $11.7 \%)$. The presence of Ectocarpus sp. increased drag on its host by a mean factor of 2.2 (= geometric mean, median 1.9). This increase of drag by Ectocarpus sp. was significant (Wilcoxon: $p=0.0076, \mathrm{n}=9$ ).

Balanus improvisus. Sixteen snails had barnacles as their main epibiont. On average, the volume of epibiotic $B$. improvisus constituted $44.9 \%$ (SD $27.4 \%$ ) of the clean host snail's volume. These epibionts increased drag by a mean factor of 1.63 (= geometric mean, median 1.85). This epibiosis-caused drag increase was highly significant (Wilcoxon: $\mathrm{p}=0.0007, \mathrm{n}=16$ ) .

These drag increases were probably caused by an increase in volume and frictional surface due to the presence of epibionts. However, the correlation between drag increase and epibiont volume was only significant for the association of snails and barnacles (Spearman: $\rho=0.71, \mathrm{p}=0.0084, \mathrm{n}=15$ ).

The different epibiotic communities did not influence drag to the same extent (Kruskal-Wallis: $\mathrm{p}=$ $0.0001, \mathrm{n}=36)$. Per unit volume $(1 \mathrm{ml})$ of epibiont, drag increased by 0.4 (SE 0.09) $\mathrm{mN}$ per $\mathrm{ml}$ barnacle, 1.5 (SE 1.4) $\mathrm{mN}$ per $\mathrm{ml}$ Enteromorpha intestinalis, 4.9 (SE 1.4) $\mathrm{mN}$ per $\mathrm{ml}$ Ectocarpus sp. and 3.2 (SE 0.9) $\mathrm{mN}$ per $\mathrm{ml}$

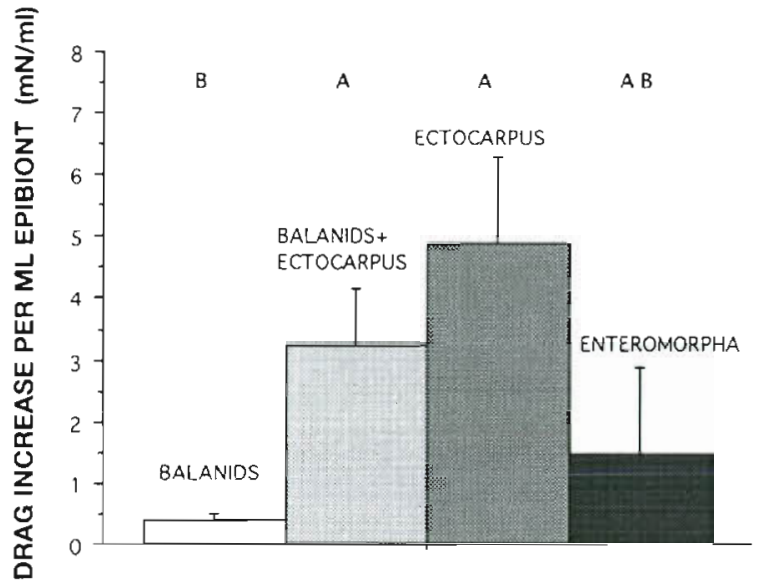

Fig. 3. Specific drag increase (per $\mathrm{ml}$ epibiont) for the 4 types of epibiotic community encountered ( \pm SE). Columns sharing the same letter at the upper margin of the graph are not significantly different from each other as tested by pairwise

$U$-test following a Kruskal-Wallis test $(p=0.0001, n=36)$

mixed balanid-Ectocarpus community (Fig. 3). A unit volume of Ectocarpus increased drag significantly more than the same volume of barnacles ( $U$-test: $\mathrm{p}=$ $0.0002, n=9+16)$ and the drag increase per unit volume of mixed balanid-Ectocarpus population was significantly greater than the influence of barnacles alone $(U$-test, $\mathrm{p}=0.0001, \mathrm{n}=9+16)$. Drag increase by $E$. intestinalis did not differ significantly from that of any other epibiont, probably due to the low number of snail replicates $(n=3)$ fouled by this alga. The drag-increase rates by a mixed balanid-Ectocarpus community and by Ectocarpus sp. alone did not differ significantly. either.

Interestingly, per unit volume the summed effects of barnacles and Ectocarpus sp. in the mixed population were greater than the sum of the expected effects of the balanid and the Ectocarpus sp. component. In other words, barnacles increase drag by $0.4 \mathrm{mN} \mathrm{ml}^{-1}$, Ectocarpus sp. by $4.9 \mathrm{mN} \mathrm{ml}^{-1}$. When a mixed epibiotic population is composed of $0.3 \mathrm{ml}$ barnacles and $0.5 \mathrm{ml}$ Ectocarpus sp., the expected drag increase is $2.57 \mathrm{mN}$. Generally, it proved to be substantially greater: by multiplying the measured volumes of the mixed balanid-Ectocarpus components on 9 snails by the specific drag increase of the components, a mean drag increase of $0.99 \mathrm{mN}$ (SE 0.14) was expected. Instead, drag increased, on average, by 1.62 (SE 0.17 ) $\mathrm{mN}$. This difference was highly significant (Wilcoxon: $p=0.0012$, $\mathrm{n}=9$ ).

\section{Growth rates of fouled and clean snails}

Between the beginning and end of the experiment, the light period increased from about 8 to $16 \mathrm{~h}$. Addi- 
Table 2. Growth data of fouled and clean snails on the 5 monitoring dates (Days $1,77,104,147$ and 168 ) and during the 4 periods (Periods A, B, C1 and C2) delimited by those dates. Significant differences between growth rates of fouled versus clean snails (2 independent samples, $U$-test) and between the growth rates of a given treatment group during 2 successive periods (dependent samples, Wilcoxon's Paired Sign test), are given in bold type

\begin{tabular}{|c|c|c|c|c|c|c|c|c|c|}
\hline \multirow{2}{*}{$\begin{array}{l}\text { Date (day) } \\
\text { or Period } \\
(A, B, C)\end{array}$} & \multicolumn{3}{|c|}{ Mean width [mm (SE)] } & \multicolumn{3}{|c|}{ Growth rate $\left\{\mu \mathrm{m} \mathrm{d}^{-1}(\mathrm{SE})\right\rfloor$} & \multicolumn{3}{|c|}{$\begin{array}{l}\text { Difference between growth rates of } \\
\left.\text { successive periods }\left[\mu \mathrm{m} \mathrm{d}^{-1} \text { (Wilcoxon } \mathrm{p}\right)\right]\end{array}$} \\
\hline & Fouled & Clean & $U$-test $p$ & Fouled & Clean & $U$-test $\mathrm{p}$ & Periods & Fouled & Clean \\
\hline 1 & $11.50(0.4)$ & $11.21(0.4)$ & 0.73 & & & & & & \\
\hline $\mathrm{A}(1 \rightarrow 77)$ & & & & $4.3(1.2)$ & $7.7(1.0)$ & 0.01 & & & \\
\hline $77^{\circ}$ & $11.83(0.3)$ & $11.8 \quad(0.4)$ & 0.97 & & & & A to $B$ & $+2.4(p=0.25)$ & $-7.3(p=0.04)$ \\
\hline $\mathrm{B}(77 \rightarrow 104)$ & & & & $6.7(1.7)$ & $0.4(3.1)$ & 0.19 & & & \\
\hline $104^{\mathrm{a}}$ & $12.0 \quad(0.3)$ & $11.81(0.3)$ & 0.71 & & & & $\mathrm{~B}$ to $\mathrm{Cl}$ & $-6.5(p=0.01)$ & $+2.1(p=0.59)$ \\
\hline $104^{\mathrm{b}}$ & $12.11(0.3)$ & $11.74(0.4)$ & 0.41 & & & & & & \\
\hline C1 $(104 \rightarrow 147)$ & & & & $0.2(2.1)$ & $2.3(2.1)$ & 0.28 & & & \\
\hline 147 & $12.12(0.2)$ & $11.84(0.3)$ & 0.51 & & & & $\mathrm{C} 1$ to $\mathrm{C} 2$ & $+7.1(p=0.02)$ & $+12.1(\mathrm{p}=0.04)$ \\
\hline $\mathrm{C} 2(147 \rightarrow 168)$ & & & & $7.6(2.9)$ & $14.8(5.2)$ & 0.3 & & & \\
\hline 168 & $12.28(0.2)$ & $12.16(0.25)$ & 0.82 & & & & & & \\
\hline$A \rightarrow C 2(168 d)$ & & & & $4.0(1.5)$ & $6.2(1.1)$ & 0.048 & & & \\
\hline
\end{tabular}

tionally, the sequential experimental periods $\mathrm{A}, \mathrm{B}, \mathrm{C} 1$ and $\mathrm{C} 2$ were characterized by drastic differences in natural and artificially controlled food abundance (see 'Material and methods'). Period A is defined by low temperature, low light and low food. During Period B, the snails were exposed to medium light, medium temperature and over-abundant food. Period C is defined by high light levels, higher temperature and artificially reduced food ('sparse' in C1, 'sparse to abundant' in C2).

\section{All-snail data}

During the $168 \mathrm{~d}$ in the flume, the snails grew continuously, although with changing rates (Table 2, Fig. 4). Mean growth rate over the whole duration of the experiment was 5.0 (SE 0.97) $\mu \mathrm{m}$ shell width $\mathrm{d}^{-1}$.

During Period A, mean growth rate was 5.9 (SE 0.8) $\mu \mathrm{m} \mathrm{d}^{-1}$. During Period B, the snails grew by 3.7 (SE 1.8)

Table 3. Age-independant growth of fouled and clean snails. The Bertalanffy growth coefficient $K$ eliminates the age-based bias on growth rates. Significant differences in bold type

\begin{tabular}{|c|c|c|c|c|}
\hline \multirow[t]{2}{*}{ Period } & \multicolumn{4}{|c|}{ Bertalanffy growth coefficient $K\left[\times 10^{-3} \mathrm{~d}^{-1},(\mathrm{SE})\right]$} \\
\hline & All snails & Clean snails & Fouled snails & $U$-test $\mathrm{p}$ \\
\hline A & $1.1(0.14)$ & $1.4(0.2)$ & $0.77(0.16)$ & $<0.05$ \\
\hline B & $0.95(0.21)$ & $0.62(0.27)$ & $1.2(0.29)$ & 0.1 \\
\hline $\mathrm{C} 1^{\mathrm{a}}$ & $0.50(0.18)$ & $0.66(0.23)$ & $0.37(0.27)$ & 0.2 \\
\hline $\mathrm{C} 2^{\mathrm{a}}$ & $2.1(0.47)$ & $2.6(0.81)$ & $1.6(0.52)$ & 0.3 \\
\hline $\mathrm{A} \rightarrow \mathrm{C} 2^{\mathrm{a}}$ & $0.81(0.12)$ & $0.99(0.14)$ & $0.65(0.19)$ & $<0.05$ \\
\hline
\end{tabular}

$\mu \mathrm{m} \mathrm{d}^{-1}$. In Period C, an initial slow-growth phase (C1: $1.22 \pm 1.5 \mu \mathrm{m} \mathrm{d}^{-1}$ ) was followed by a phase of accelerated growth (C2: $\left.11.03 \pm 2.9 \mu \mathrm{m} \mathrm{d}^{-1}\right)$.

Generally, small snails of both treatment groups grew faster then bigger snails $(p=0.0002$, Tables $2 \&$ 3). This correlation was not significant during Periods $A$ and $\mathrm{C} 2$. The Bertalanffy growth coefficient $K$ neutralizes the age-related influence of snail size on growth rates. Average $K$ for all snails over the entire duration of the flume experiment was $0.81 \times 10^{-3}$ (SE $\left.0.12 \times 10^{-3}\right)$

\section{Comparison between fouled and clean snail groups}

Both snail groups showed a significant correlation between shell size and growth rate when the entire 168 d growth phase was viewed. During the single periods the correlation was less clear. During Period A, when growth rates between clean and fouled snails differed significantly, clean snails in contrast to fouled snails even exhibited a (non-significant) positive correlation between the 2 parameters. At no time did shell size differ significantly between fouled and clean snails (Table 2). Thus, any size effect on growth should act similarly on both treatment groups (see below).

Growth rates varied both between snail groups during a given growth period ('parallel'), as well as within each group between successive periods ('serial'). Some of these differences were not significant (Table 2). 


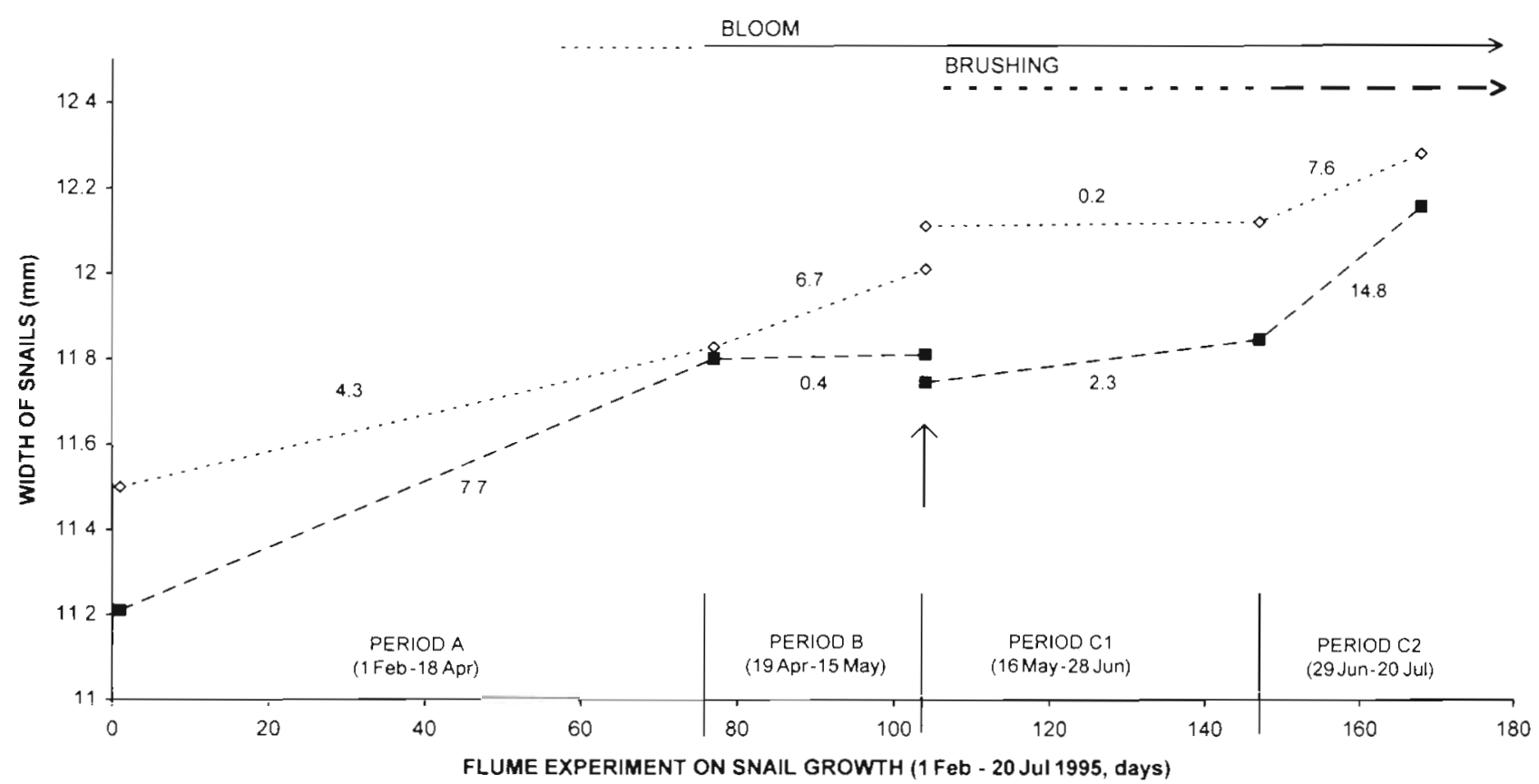

Fig. 4. Growth of fouled ( $\diamond$ ) and clean ( $\mathbf{0}$ ) snails between February and July 1995 (Days 1 through 168, and Periods A through C2). Standard errors have been left out for clarity's sake, but can be found in Table 2 . Growth rates ( $\mu$ m $\mathrm{d}^{-1}$ ) for each snail type and each period are given in the graph. For monitoring Day 104 (vertical arrow) a double set of data is given: the first is mean shell widths including, the second excluding, snails 4 and 15, which died in Period C1. During Period A and over the entire experimental period, clean snails grew significantly faster than fouled snails

Depending on the factors 'aufwuchs' (with or without) and period (A through $\mathrm{C} 2$ ), the growth rates of the 2 snail groups differed significantly (Friedman: $\mathrm{p}=$ 0.002 ), as analyzed in more detail hereafter.

Serial differences in growth rates (Figs. 4 \& 5): Fouled snails grew relatively slowly during Period A, then showed non-significantly accelerated growth during Period B. After a sharp and significant decrease of growth rates during $\mathrm{C} 1$, growth accelerated again significantly during $\mathrm{C} 2$. Clean snails grew fast during Period A, growth rates declined drastically and significantly during Period B. During Period $\mathrm{C}$ growth accelerated first insignificantly (C1) then sharply and significantly during $\mathrm{C} 2$. Thus, under changing conditions the growth rates of fouled and clean snails behave somewhat complementarily (with the exception of Period C2).

Parallel differences in growth rates (Figs. 4 \& 5 , Table 2): Viewing the entire 5 mo period, fouled snails grew more slowly $\left(4.0 \mu \mathrm{m} \mathrm{d}^{-1}\right.$, SE 1.5$)$ than clean snails $\left(6.2 \mu \mathrm{m} \mathrm{d}^{-1}, \mathrm{SE} 1.1\right)$. Compensating for the influence of snail size on growth rates, the Bertalanffy growth coefficient differed similarly: $K_{\text {fouled }}=0.65 \times 10^{-3} \mathrm{~d}^{-1}$, whereas $K_{\text {clean }}=0.99 \times 10^{-3} \mathrm{~d}^{-1}$ The fact that growth differences between snail groups were almost identical whether expressed as crude growth rates (Table 2) or as Bertalanffy coefficients (Table 3) shows that they are not caused by slight differences of mean size between treatment groups. Thus, freed of any age- based bias or not, clean snails grew 1.5 times faster than fouled snails. These differences were significant ( $U$-test: $p \leq 0.05)$, in spite of wide variations of growth rates in the different periods (Fig. 5).

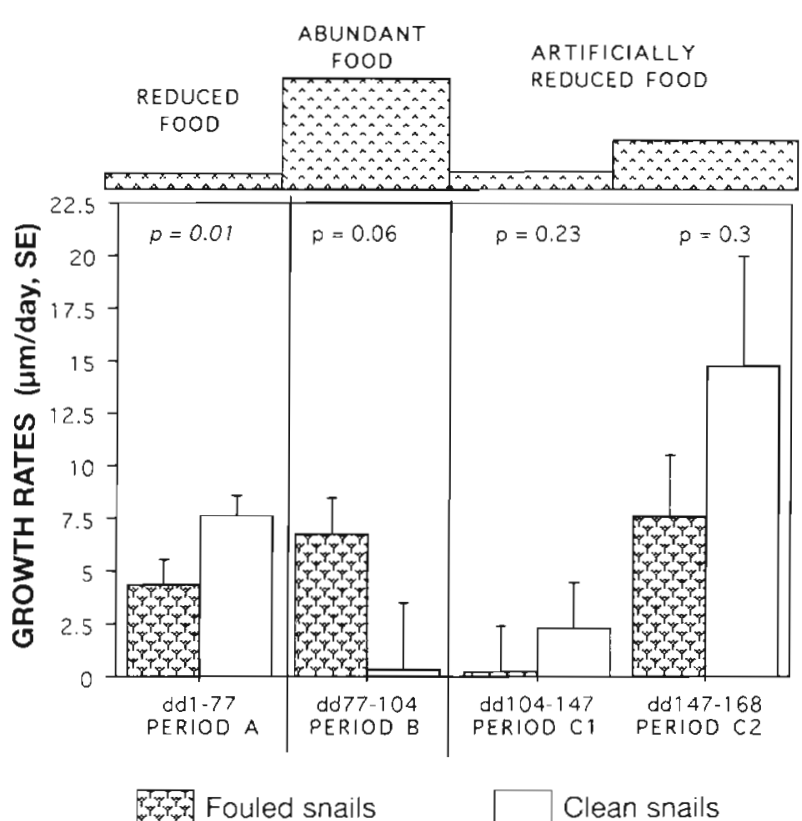

Fig. 5. Growth rates of shell widths for clean and fouled snails during periods of varying food abundance, the latter symbolized by the shaded areas at the top of the graph $(\mathrm{p}=U$-test significance of difference) 
During Period A, clean snails grew significantly faster than fouled snails. During Periods B through C2, the differences in growth rates were not significant.

Parallel differences of other parameters: The analysis of snail dry weight, shell dry weight and operculum area at the end of the experiment revealed several morphometric differences between treatment groups. In fouled snails, the ratio of body mass to shell mass was significantly smaller than for clean snails 10.077 (SE 0.005) vs 0.098 (SE 0.005), $U$-test: $p=0.02$ ).

The relation between shell weight and size is comparable in the 2 snail groups (U-test, $\mathrm{p}=0.21$ ). The opercula of the 2 groups did not differ in size. Consequently, while having similar shell mass, fouled snails seem to be leaner than clean snails after having been exposed to a moderate current for 5 mo.

\section{DISCUSSION}

This investigation provides evidence that, under conditions of moderate and steady flow, epibionts have the potential to increase drag on their hosts substantially, and that fouled snails grow more slowly than clean conspecifics.

All results were obtained using a water velocity of $8 \mathrm{~cm} \mathrm{~s}^{-1}$. In some Littorina littorea habitats substantially higher velocities may occur. Thus, in North Sea tidal flats current speeds up to $100 \mathrm{~cm} \mathrm{~s}^{-1}$ are common (K. Anger pers. comm.), and velocities of 1 to $10 \mathrm{~m} \mathrm{~s}^{-1}$ are not rare on exposed coasts or habitats subject to tidal currents (Denny 1985, Gaylord et al. 1994). I chose to work with a considerably slower current in order to ensure low turbulence conditions and not to overstress the snails, which in the growth experiment were constantly exposed to flow over $5 \mathrm{mo}$, and not rhythmically or sporadically as in many natural habitats. On the other hand, the artificial aufwuchs in the growth experiment increased drag more (factor 4) than the natural aufwuchs on the snail population studied (factor 2). Thus, these snails experienced drag values presumably similar to conditions of higher water velocities or more aufwuchs, both of which frequently occur.

Organisms in flow experience 3 types of hydrodynamic forces: drag, lift and acceleration (Gaylord et al. 1994). The last is zero in this study's steady flow regime. Lift was neglected in this study, because its relative importance decreases with lower Reynolds numbers (Vogel 1981). Besides, even at $16 \mathrm{~cm} \mathrm{~s}^{-1}$ detached snails were not raised in any way, showing that their weight far exceeded any vertical lift component at the velocity used here. Drag should thus be the hydrodynamic force with the greatest ecological significance for periwinkles in slow and steady flow.

\section{Drag on clean and fouled Littorina littorea}

This study shows that clean Littorina littorea do experience drag in the order of $1 \mathrm{mN}$ at $8 \mathrm{~cm} \mathrm{~s}^{-1}$, and that drag increases almost linearly with velocity (for the very restricted range assessed: 6 to $16 \mathrm{~cm} \mathrm{~s}^{-1}$ ). These data compare well with drag on limpets of similar size as deduced from Fig. 3 in Dudley (1985). This similarity between periwinkles and limpets indicate that at low Reynolds numbers size counts more than shape or surface characteristics, as far as drag is concerned (see also Vogel 1981).

On average, epibiosis doubled the drag of the host snail. In theory, effects on drag may be related to one or more of several drag-relevant parameters: size, surface wettability, structural complexity of surface (rugosity, topography, surface-to-size ratio) and flexibility. The only parameter I was able to quantify accurately was the volume that epibiotic growth added to the host snail (size increase). As mentioned before, this is justified under the given hydrodynamic conditions.

Different epibiotic communities increased drag to a different degree. Per added $\mathrm{ml}$ of epibiont, Ectocarpus sp. increased drag 12 times more than the same volume of Balanus improvisus and more than 3 times stronger than Enteromorpha intestinalis. At first glance, these results look surprising: because of their supposedly more slippery surface and their flexibility I had expected the algae, and in particular the filamentous Ectocarpus sp., to have a smaller effect than the rigid and rougher barnacles.

There are several possible explanations for these results: (1) While the algae are undoubtedly more flexible than the calcareous barnacles, the supposed difference in roughness has to remain purely speculative for the time being. It is conceivable that at the roughness level relevant for drag at these velocities algae are more drag-inducing than barnacles. (2) Even if balanid-covered snails were rougher than those fouled by algae, Vogel (1981) emphasizes that at Reynolds numbers below $\sim 10^{4}$ surface roughness is irrelevant for drag. The Reynolds number in this study never exceeded $10^{3}$. For limpets, Dudley (1985) also failed to find any correlation between shell sculpture and shell drag for velocities between 15 and $45 \mathrm{~cm} \mathrm{~s}^{-1}$. (3) Specific drag increase was calculated per ml epibiont. While $1 \mathrm{ml}$ of epibiotic Balanus improvisus increases volume of the compound organism (basibiont + epibionts) by just this amount, epibiotic algae, and in particular the filamentous and bushy Ectocarpus sp., entrap a significant amount of water (Gaylord et al. 1994) between their branches. At the slow current speed of this study, Ectocarpus sp. did not flatten substantially, indicating that most of the captured volume 
of water remained between the filaments of the alga. Thus, $1 \mathrm{ml}$ of Ectocarpus sp. thallus probably represents a volume increase of the fouled snail several times this value. This would not apply in the same magnitude to the sparse and unbranched ongrowth of $E$. intestinalis. At higher velocities, the squeezing out of entrapped water may in part explain the inverse correlation between algal drag coefficients and current speed reported by Gaylord et al. (1994). (4) The flexible algae tended to flutter in the current. Fluttering objects increase drag more than rigid ones, especially in steady flow (Vogel 1981). (5) The barnacles were much smaller (height 2 to $8 \mathrm{~mm}$ ) than the algae (length 10 to $50 \mathrm{~mm}$ ). Consequently, a relatively larger portion of the barnacles was sheltered within the $5 \mathrm{~mm}$ boundary layer around the snail shell, while the longer algae presumably extended well into main stream, at least with the plant parts extending beyond the snail shell (as ililustrated by their fluttering). (6) Finally, the surface-to-volume ratio is likely to be substantially greater for the slender and/or branched algae than for the cone-shaped barnacles. Consequently, per ml of epibiont frictional surface should increase more dramatically in the case of algal fouling

In summary, I believe that, for a given volume of aufwuchs, drag on fouled snails was increased more by Ectocarpus sp. than by Balanus improvisus, because the first tended to flutter, had a larger frictional surface, extended farther into the main stream and entrapped additional volumes of water.

A further result calls for comment: a mixed aufwuchs composed of Ectocarpus sp. and Balanus improvisus increased drag significantly more (by $64 \%$ ) than the sum of the isolated effects of these epibionts. This synergetic effect may have been caused by an observably different reconfiguration-in-flow of the algae in the 2 scenarios. In a monospecific aufwuchs situation, the current tended to bend the algae toward the substratum (snail), so that their basal parts, at least, were closer to the shell surface than in stationary water. In a mixed aufwuchs, the barnacles growing between the basal parts of the algae impeded this reconfiguration to some extent. We may speculate that, as a consequence, less of the still water between the plants was squeezed out, the streamlining was hindered and the drag coefficient remained greater (Gaylord et al. 1994). Furthermore, even the basal parts of the algae were kept at a greater distance from the shell surface and a larger portion of the plants was exposed to full main stream velocities.

In another group of snails, additional aufwuchs components had no influence on the drag of balanid-fouled Littorina littorea: a thin $(<3 \mathrm{~mm})$ epibiotic crust composed of algae, ciliates, hydropolyps, scyphopolyps, sedentary polychaetes and juvenile mussels grew between barnacles. These epibionts did not measurably increase drag beyond the balanid effect, although they represented about $15 \%$ of the balanid volume. One likely reason for the absence of any drag-increasing effect by these subdominant epibionts is that the crust they formed lay well within the boundary layer between the barnacles.

\section{Growth of clean and fouled Littorina littorea}

During the in situ growth experiment, clean snails and snails bearing artificial aufwuchs lived in a steady and moderate current for $5 \mathrm{mo}$. The areas available for grazing did not overlap and were of the same size for each snail. Over the entire $168 \mathrm{~d}$, snails grew at an average rate of $5.0 \mu \mathrm{m}$ width increase and $5.2 \mu \mathrm{m}$ length increase per day. This is 3 to 7 times slower than natural growth rates reported: in the field, Littorina littorea has been found to grow in width by 18 to $35 \mu \mathrm{m}$ $\mathrm{d}^{-1}$ and in length by $28 \mu \mathrm{m} \mathrm{d}^{-1}$ (calculated from data in Kemp \& Bertness 1984, New England coast, USA, June to September 1982, and in Ekaratne \& Crisp 1984, sheltered English coast, summer 1981). It is conceivable that (among numerous other possible reasons) the flume snails grew slower because they were continuously exposed to drag without being able to seek shelter in crevices or beneath algae.

Growth rates correlated negatively with snail size. In both treatment groups smaller snails grew faster than larger individuals. Ekaratne \& Crisp (1984) have reported that growth rates in Littorina littorea decrease with age. The flume snails of my investigation only covered about $1 / 4$ (maximum range $3.5 \mathrm{~mm}$ ) of the size range these authors analyzed. I doubt that the strong correlation between size and growth rates observed in the present study can solely be explained by this age effect. Possibly, it was enhanced by a sheltering effect of the boundary layer (Weissenberger et al. 1991): the smaller a snail, the deeper it lives within the boundary layer covering a solid surface. The thickness of this layer of reduced water velocities 10 to $99 \%$ main stream velocity) on the bottom plate of the experimental section ranged approximately from 5 to $17.5 \mathrm{~mm}$, initial shell lengths from 12.5 to $18.5 \mathrm{~mm}$. Small individuals would thus experience disproportionately lower drag. This size effect affects both treatment groups similarly and has no bearing on the observed difference of growth rates between fouled and clean snails.

The only parameter by which the 2 groups of snails initially differed was drag (4 times less on clean snails). Viewing the entire growth period of $168 \mathrm{~d}$, fouled snails grew slower by $35 \%$ than clean snails. Cleaned of any age-based bias by employing Bertalanffy's 
coefficient $K$, this difference is $34 \%$. Both results are significant.

Strong within-group variations of growth rates in the course of the experiment were observed. I believe that these were caused mainly by drastic changes in the amount of food available to the snails during subsequent periods. For nutrition, the snails depended on prey settling within their grazing areas.

The 2 snail groups responded very clearly, albeit often in an complementary way, to the changes in food availability (Fig. 4). With the exception of Period B, when more food was available than the snails could consume, clean snails grew faster (not always significantly) than fouled snails. Additional metabolic costs inflicted by epibiosis-caused drag increase could explain these results.

According to Davies et al. (1992) the energy budget of Littorina littorea is composed as follows:

$$
C=P_{\mathrm{g}}+P_{\mathrm{r}}+R+F+U+M
$$

where $C$ is consumption, $P_{\mathrm{g}}$ is somatic growth, $P_{\mathrm{r}}$ is reproductive investment, $R$ is respiration, $F$ is faeces, $U$ is excretion, $M$ is mucus production. Defense costs do not figure in this equation, but as reported in a previous article (Wahl \& Sönnichsen 1992), there is no indication that $L$. littorea does defend itself.

Throughout the experiment, clean (subscript C) and fouled (subscript F) snails grazed same-sized areas bearing identical food to the same extent: $C_{F}=C_{C}$. Let us for the moment assume that reproductive investment was the same in both treatment groups: $P_{\mathrm{rF}} \approx P_{\mathrm{rc}}$. (I tried to assess gonad mass per snail at the end of the growth experiment. However, in Littorina littorea ovary and testis are so closely entangled with the digestive gland that a quantitatively exact extraction proved impossible. However, no between-group differences in gonad size were obvious to the eye.) Consequently, the between-group differences in growth rates $P_{\mathrm{gF}}<P_{\mathrm{gC}}$ must be due to

$$
(R+F+U)_{F}+M_{F}>(R+F+U)_{C}+M_{C}
$$

Pedal muscle activity affects the first term, pedal mucus production the second term on either side of the inequality. Increased drag on fouled snails seems to act in this manner. In this study, growth reduction was not caused by reduced consumption, as reported for fouled limpets in flow (Judge 1988). During Period B (food overabundance), between-group difference of growth rates was temporarily inversed. For the time being, this cannot be explained.

The fact that differences in growth rates between the 2 snail groups were not significant during Period $C$ may have several reasons: (1) Due to the deaths of 2 snails during Period C1, N diminished. (2) For limpets, foot muscle activity improves with temperature
(Grenon \& Walker 1981). If this also applies to Littorina littorea, more muscle must have done the same work in Period A than in the substantially warmer Period C, which would have enhanced the metabolic disadvantage of fouled snails in winter/spring. (3) During Period A, food shortage was most severe, enhancing the relative impact of presumably higher locomotion/adhesion costs for fouled snails.

After 5 mo of exposure to a moderate current, fouled snails were leaner Their ratio of body dry weight to shell dry weight was significantly lower, by $22 \%$, than for clean snails. This suggests that with regard to growth, drag-stressed fouled snails invested more into shell mass and, possibly, foot muscle (operculum area not reduced in contrast to rest of snail body) than into other organs, such as fat reserves or gonads.

In conclusion, the investigation presented here shows that epibionts may increase drag on periwinkles substantially, and that fouled snails living in a slow and steady flow regime grow slower than clean conspecifics when food is limited.

In the high-velocity intertidal of Helgoland, Littorina littorea is significantly less fouled than its conspecifics in the calmer Western Baltic. Previously, we have explained this by different rates of mutual grazing in the 2 localities (Wahl \& Sönnichsen 1992). An additional reason could be that heavily fouled snails survive less well in high-velocity habitats. Increased drag (including accelerational forces!) would raise the risk of dislodgment (e.g. Witman \& Suchanek 1984, Ansell et al. 1988). Additionally, small snails are more susceptible to predation and the reduction of growth rates by aufwuchs would prolong this dangerous phase and thus, presumably, increase mortality of fouled snails.

Acknowledgements. I am grateful for the critical comments of Markus Hüttel (MPl, Bremen) and of 3 anonymous reviewers, which substantually improved the manuscript.

\section{LITERATURE CITED}

Ansell AD, Robb L, Powell HT (1988) Algal-induced dislodgement as a cause of bivalve mortality on some Scottish beaches. J Mar Biol Ass UK 68:219-233

Barkai A, McQuaid C (1988) Predator-prey role reversal un a marine benthic ecosystem. Science 242:62-64

Bloom SA (1975) The motile escape response of a sessile prey: a sponge-scallop mutualism. J Exp Mar Biol Ecol 17: $311-321$

Davies MS, Jones HD, Hawkins SJ (1992) Pedal mucus production in Littorina littorea. In: Graham J, Mill PJ, Greid D (eds) Proc 3rd Int Symp Littorinid Biol. The Malacological Soc, London, p 227-233

Dayton PK (1971) Competition, disturbance and community organisation: the provision and subsequent utilization of space in a rocky intertidal community. Ecol Monogr 41: 351-389 
Denny MW (1985) Wave forces on intertidal organisms: a case study. Limnol Oceanogr 30 (6):1171-1187

Dudley R (1985) Fluid-dynamic drag on limpet shells. Veliger $28(1): 6-13$

Ekaratne SUK, Crisp DJ (1984) Seasonal growth studies of intertidal gastropods from shell micro-growth band measurements, including a comparison within alternative methods. J Mar Biol Ass UK 64:183-210

Feifarek BP (1987) Spines and epibionts as antipredator defenses in the thorny oyster Spondylus americanus Hermann. J Exp Mar Biol Ecol 105:39-56

Gaylord B, Blanchette CA, Denny MW (1994) Mechanical consequences of size in wave-swept algae. Ecol Monogr $64(3): 28-313$

Grenon JF, Walker $G$ (1981) The tenacity of the limpet, Patella vulgata L.: an experimental approach. J Exp Mar Biol Ecol $54: 277-308$

Judge ML (1988) The effects of increased drag on Lottia gigantea (Sowerby 1834) on foraging behaviour. Funct Ecol 2:363-369

Kemp P, Bertness MD (1984) Snail shape and growth rates: evidence for plastic shell allometry in Littorina littorea. Proc Natl Acad Sci USA 81:811-813

Nowell ARM, Jumars PA (1987) Flumes: theoretical and experimental considerations for simulation of benthic

This article was submitted to the editor environments. Oceanogr Mar Biol A Rev 25:91-112

Penhale PA (1977) Macrophyte-epiphyte biomass and productivity in an eelgrass (Zostera marina L.) community. J Exp Mar Biol Ecol 26:211-224

Sar N, Rosenberg E (1987) Fish skin bacteria: colonial and cellular hydrophobicity. Microb Ecol 13:193-202

Vance RR (1978) A mutualistic interaction between a sessile marine clam and its epibionts. Ecology 59 (4):679-685

Vogel S (1981) Life in moving fluids. Princeton Univ Press, Princeton, NJ

Wahl M (1989) Marine epibiosis. I. Fouling and antifouling: some basic aspects. Mar Ecol Prog Ser 58:175-189

Wahl M, Hay ME (1995) Associational resistance and shared doom. Oecologia 102:329-340

Wahl M, Sönnichsen H (1992) Marine epibiosis. IV The periwinkle Littorina littorea lacks typical antifouling defences - why are some populations so little fouled? Mar Ecol Prog Ser 88:225-235

Weissenberger J, Spatz HC, Emanns A, Schwoerbel J (1991) Measurement of lift and drag forces in the $\mathrm{mN}$ range experienced by benthic arthropods at flow velocities below $12 \mathrm{~m} / \mathrm{s}$. Freshwat Biol 25:21-31

Witman JD, Suchanek TH (1984) Mussels in flow: drag and dislodgement by epizoans. Mar Ecol Prog Ser 16 $259-268$

Manuscript first received: January 9, 1996

Revised version accepted: April 19, 1996 